\title{
Cultural Characters and Serological Relationships of Some Mycoplasmas Isolated from Bovine Sources
}

\author{
By N. C. JAIN, D. E. JASPER AND J. D. DELLINGER \\ Department of Clinical Pathology, School of Veterinary Medicine, \\ University of California, Davis, California, U.S.A.
}

(Accepted for publication 7 June 1967)

\begin{abstract}
SUMMARY
Cultural characteristics and serological relationships of mycoplasmas from the bovine vagina, mastitic milk, and other sources were studied. Parasitic strains could be distinguished from saprophytic strains in that they required incorporation of horse serum into the PPLO agar for growth, produced surface crystallization on PPLO agar and did not ferment carbohydrates. All strains were haemolytic for red blood cells of the guinea pig, rabbit, sheep, cow and horse. Satellite growth enhancement was seen only with the strains associated with mastitis.

Rabbit antisera to each mycoplasma were tested against homologous and heterologous strains for precipitins and for growth inhibitory antibodies. Four serotypes were distinguished among the bovine isolates by agar-gel double-diffusion technique. Growth inhibitory antibodies were detected in homologous antisera against only four of the strains studied.
\end{abstract}

\section{INTRODUCTION}

Recent reports from England of bovine mastitis due to mycoplasmas (Davidson \& Stuart, 1960; Stuart et al. 1963; Bruford et al. 1965), from the United States (Hale, Helmboldt, Plastridge \& Stula, 1962; Carmichael et al. 1963; Fincher, I964; Stern \& Harris, 1964; Jasper, Jain \& Brazil, 1966) and from Israel (Bar-Moshe, I964) have provided a detailed description of the disease, but only limited descriptions of serological, morphological and biochemical characteristics of the agents involved. The recognition of mycoplasma as a causative agent of bovine mastitis, arthritis, respiratory and genital infections has stimulated frequent culturing of milk and other body fluids or tissues for mycoplasma. The resultant frequency of recovery of mycoplasma from clinical or normal conditions in cattle requires a determination of distinguishing characteristics by which the organism can, at least in part, be identified and classified. In the present work some of the cultural, morphological, biochemical and immunological characteristics of certain mycoplasmas from bovine mastitic milk, the reproductive tract, and other sources were determined in a search for reliable criteria for classification of mastitis pathogens and other isolates from bovines.

\section{METHODS}

Mycoplasma strains. The mycoplasmas used in this study include seven isolates from California (Table I). Four of these isolates (OI, I042, II82, I336) were from milk from cows with mastitis in the reported epizootic (Jasper et al. I966); the isolate 1063 
was from a bulk tank milk sample from another location (Jasper et al. I966); and the two vaginal isolates ( 1367,1370 ) were from a dairy herd with an infertility problem. These isolates were compared with four bovine, a human and a saprophytic strain obtained from other investigators.

\section{Table I. Source of Mycoplasma strains}

\begin{tabular}{|c|c|c|}
\hline Mycoplasma & Recovery site & Source \\
\hline OI, $1042,1182,1336$ & Bovine mastitic milk & $\begin{array}{l}\text { Isolated in our laboratory (Jasper et al. } \\
\text { I966) }\end{array}$ \\
\hline 1063 & Bulk tank milk & Jasper et al. (1966) \\
\hline 1367,1370 & Bovine vagina & Recently isolated in our laboratory \\
\hline Strain ' $56 \mathrm{R}$ ' & Bovine mastitic milk & $\begin{array}{l}\text { Dr L. E. Carmichael, Cornell Univ., } \\
\text { Ithaca, N.Y. }\end{array}$ \\
\hline Strain 'WIDANKA F' & Bovine mastitic milk & Dr L. E. Carmichael \\
\hline Connecticut strain & Bovine mastitic milk & $\begin{array}{l}\text { Dr R. S. Hirth, Univ. Connecticut, } \\
\text { Storrs, Conn. }\end{array}$ \\
\hline $\begin{array}{l}\text { M. bovigenitalium strain } \\
\text { PG-I I }\end{array}$ & Bovine vagina & Dr J. G. Tully, NIH, Bethesda, Md. \\
\hline M. pharyngis strain PATT & Normal human & $\begin{array}{l}\text { Dr W. A. Clyde, Jr., Univ. North } \\
\text { Carolina, Chapel Hill, N.C. }\end{array}$ \\
\hline M. laidlawii & Chicken sinus & $\begin{array}{l}\text { Dr H. E. Adler, Univ. California, Davis, } \\
\text { California }\end{array}$ \\
\hline
\end{tabular}

Basic cultural procedures. Agar plates used for surface inoculations contained $20 \mathrm{ml}$. Bacto PPLO agar (Difco) supplemented with I \% (w/v) yeast autolysate and $15 \%(\mathrm{v} / \mathrm{v})$ horse serum. Agar plate cultures were routinely incubated at $37^{\circ}$ in an atmosphere containing approximately $10 \%(\mathrm{v} / \mathrm{v}) \mathrm{CO}_{2}+90 \%(\mathrm{v} / \mathrm{v})$ air in a moist chamber, and were read after 3 days. Stock cultures of mycoplasmas (broth cultures prepared from an isolated colony of a mycoplasma grown on PPLO agar) were maintained in tubes containing a slope of $2 \mathrm{ml}$. of PPLO agar made with $5 \%(\mathrm{v} / \mathrm{v})$ horse blood overlaid with $5 \mathrm{ml}$. standard broth medium (SBM). The SBM consisted of Bacto PPLO broth (Difco) containing $0.5 \mathrm{~g}$. glucose, I g. yeast autolysate, $20 \mathrm{ml}$. horse serum, and 100,000 units penicillin $\mathrm{G}$ (potassium) per $100 \mathrm{ml}$., adjusted to $\mathrm{pH} 7 \cdot 8$. Serial transfers of stock cultures were usually made after storage at $4^{\circ}$ for $3-4$ weeks, but occasionally at shorter intervals. Transfers for the various experiments were made after 3-5 days growth in SBM. Broth cultures were incubated in air.

Colonial and cellular morphology. Gross examination of growth on PPLO agar plates and in broth medium was made daily for 3 days. Cellular morphology was studied by light microscopy on Wright-Leishman-stained (Jasper et al. I966) coverslip smears prepared from sediments obtained from SBM cultures centrifuged at $12,000 \mathrm{~g}$ for $30 \mathrm{~min}$. Wet preparations were also examined under light and phase-contrast microscopes.

Morphological characteristics of isolated colonies on agar plates were usually recorded after 3 days at $37^{\circ}$, but were sometimes supplemented by further observations after a week at room temperature. Unstained colonies and colonies stained with Dienes stain (Madoff, I959) were examined under a microscope at $\times$ roo magnification.

Differences in growth of mycoplasma on plates incubated in air and in air containing $10 \%(\mathrm{v} / \mathrm{v}) \mathrm{CO}_{2}$ were recorded. 
Haemolysis. Haemolytic activity of mycoplasma for washed red blood cells of the cow, sheep, horse, rabbit and guinea pig was determined on PPLO agar medium (Tully, 1965).

Serum requirement. Plates prepared from PPLO agar containing horse serum in o $2 \cdot 5,5,10$ and $15 \%(v / v)$ concentrations were streaked with a 3 -day growth of mycoplasma in SBM. Growth was recorded after 3 days at $37^{\circ}$, and, depending on the amount of the growth, arbitrary values of $\mathrm{I}+, 2+, 3+$ or $4+$ were assigned.

Satellite growth. Two-tenths $\mathrm{ml}$. of a 3-day broth culture of a mycoplasma was evenly spread with a glass-rod on duplicate PPLO agar plates until dry. Then a narrow streak of a $24 \mathrm{hr}$ culture of a coagulase-positive, $\alpha \beta$ haemolytic staphylococcus was made across the plate. One set of the plates was incubated in air, and the other in air $+10 \%(\mathrm{v} / \mathrm{v}) \mathrm{CO}_{2}$ in a moist chamber at $37^{\circ}$. After 3 days the plates were examined grossly and under a dissecting microscope for enhancement of growth near the staphylococcal streak (Morton, Smith \& Leberman, 1949; Dinter, Danielsson \& Bakos, 1965).

Biochemical reactions. The basal medium used for sugar fermentations consisted of PPLO broth containing I $\%(\mathrm{v} / \mathrm{v})$ ethanolic phenol red $(\mathrm{I} \%, \mathrm{w} / \mathrm{v}$, solution) as an indicator. Test sugars were added in $0.5 \%(\mathrm{w} / \mathrm{v})$ final concentration, adjusted to $\mathrm{pH}$ $7 \cdot 6$, and the medium sterilized by autoclaving. After cooling to $52^{\circ}$, the medium was supplemented with $20 \mathrm{ml}$. sterile heated horse serum ( $56^{\circ}$ for $30 \mathrm{~min}$.) and I00,000 units of penicillin $\mathrm{G}$ (potassium)/ $100 \mathrm{ml}$, and dispensed in tubes in $5 \mathrm{ml}$. amounts. Before inoculations for sugar fermentation studies, at least three serial transfers of each mycoplasma were made in SBM containing heated horse serum, but without yeast autolysate and glucose. The difficulty experienced in adapting some of the organisms to grow without yeast autolysate was overcome by further serial subculturing in this medium at 3-day intervals. Each set of sugar tubes received $0.2 \mathrm{ml}$. broth culture of each mycoplasma, and change in colour and $\mathrm{pH}$ value (Beckman $\mathrm{pH}$ Meter, Model 72 , Beckman Instrument Co., Palo Alto, Calif.) was recorded after incubation at $37^{\circ}$ for 7 days. Growth of organisms in sugar tubes was confirmed by plating a loopful of medium from the glucose tube after 3 days and 7 days of incubation. Two sets of uninoculated control sugar tubes were included in each series.

Gelatin liquefaction was tested in tubes containing Io $\mathrm{ml}$. of SMB and a small sterile piece $(15 \times 6 \times 2 \mathrm{~mm}$.) of gelatin + charcoal gel $(\mathrm{Kohn}, 1953)$. The tubes were inoculated with $0.2 \mathrm{ml}$. of a mycoplasma culture, and were read along with control tubes after 7 days at $37^{\circ}$.

Catalase production was determined on PPLO agar medium (O'Berry, Bryner \& Frank, I966). Methylene-blue reduction was tested in SBM and the time of complete decolorization of the medium recorded (Tully, 1965).

Serological procedures. Growth-inhibitory antibodies were tested by a modified filter-paper disc method (Clyde, I964). A sterile $6 \mathrm{~mm}$. diam. Bacto concentration disc (sterile blank) (Difco) was soaked in the test serum, lifted, gently touched to the edge of the tube to drain the hanging drop, and placed on an agar plate which had been evenly spread with $0 \cdot 1 \mathrm{ml}$. of a 3-day growth of mycoplasma. The zone of growth inhibition was measured after incubation for 3 days at $37^{\circ}$.

The mycoplasma antigens (for use in gel-diffusion precipitation tests and immunization of rabbits) and immune rabbit sera were prepared essentially according to the techniques used for porcine mycoplasmas (Dinter et al. 1965). Five hundred ml. of PPLO broth were inoculated with $10 \mathrm{ml}$. of a 3-day growth of a mycoplasma and 
incubated at $37^{\circ}$ for 3 days. The growth was harvested by centrifuging the culture for $30 \mathrm{~min}$. at $12,000 \mathrm{~g}$ in a refrigerated centrifuge. The sediment was washed 3 times with sterile buffered isotonic saline, resuspended in $5 \mathrm{ml}$. of sterile distilled water, distributed in $0.5 \mathrm{ml}$. amounts in small screw-capped tubes, and stored in a solid $\mathrm{CO}_{2}$ chest at approximately $-20^{\circ}$. This suspension of mycoplasma in distilled water (concentrated antigen) was frozen and thawed 5 times before use as an antigen in gel diffusion tests.

For the production of immune rabbit sera, I $\mathrm{ml}$. of the concentrated antigen was diluted to $5 \mathrm{ml}$. with sterile distilled water. Four $\mathrm{ml}$. of this diluted antigen was mixed thoroughly with an equal volume of Freund complete adjuvant (Difco). Two ml. of this adjuvant vaccine was given intramuscularly into each leg of a rabbit. After 5 weeks, I ml. of the diluted antigen (stored at $-20^{\circ}$ ) without adjuvant was injected intravenously. Rabbits were bled a week after the intravenous injection, and collected sera were stored frozen in small amounts without added preservative.

Rabbit sera were absorbed with lyophilized PPLO broth containing $20 \%(\mathrm{v} / \mathrm{v})$ horse serum by thoroughly mixing $200 \mathrm{mg}$. of the dry powder into I $\mathrm{ml}$. immune serum. The absorption was continued for 2 days at $4^{\circ}$, and sera cleared by centrifugation at $1000 \mathrm{~g}$ for $10 \mathrm{~min}$. were used in the gel-diffusion test.

A microtechnique was adopted for absorption of antisera with homologous and heterologous mycoplasma antigens in order to conserve antigen. Small quantities, about $0.0 \mathrm{I}-0.02 \mathrm{ml}$, of broth-absorbed antiserum and concentrated antigen, in ratios of $I: I$ and $I: 2$, were transferred by separate Pasteur pipettes into small screw-capped tubes. Absorption proceeded at $4^{\circ}$ for 2 days. The antiserum + antigen mixture was then used as an antiserum, and was tested against the different antigens by gel diffusion. The wells were filled 2 or 3 times with antiserum + antigen mixture, depending upon the dilution factor of the absorbed serum.

Ouchterlony's double-diffusion precipitation test was performed in Special AgarNoble (Difco) gel on glass slides (LKB Operation Manual I-6800A-E I I, LKB 6800 A Immunodiffusion Equipment, LKB Produkter AB, Stockholm I2, Sweden). The reactants were allowed to diffuse at room temperature for 2-5 days, and sometimes at $4^{\circ}$ for 2 days and the precipitation patterns recorded. The number and density of precipitation lines formed were found to vary somewhat with the length of time allowed for diffusion. Sharper lines were obtained at $4^{\circ}$. Photographs were taken without staining.

\section{RESULTS}

\section{Cultural characters}

A 3-day growth of mycoplasma in PPLO broth was easily recognized by a uniform diffuse turbidity of the medium, a thin fragile pellicle and a slight fine sediment. When horse blood agar slopes overlaid with PPLO broth were used, a change in colour of the medium from pale yellow to light green occurred. After storage at $4^{\circ}$ for $2-3$ weeks, clearing of the slopes, starting from top to bottom, was observed with the vaginal isolates (1367, 1370), but not with the others. These strains and Mycoplasma bovigenitalium did not grow as well in broth as did the other strains. A 3-day broth culture of $M$. bovigenitalium contained about $10^{6}$ colony-forming units $/ \mathrm{ml}$. as compared to $10^{8}-10^{9}$ for the mastitis strain oI.

Incorporation of horse serum in PPLO agar was essential for growth of all strains except Mycoplasma laidlawii which grew well, and strain 1063 which grew poorly, 
without horse serum. Growth was better on medium containing $10-15 \%(\mathrm{v} / \mathrm{v})$ horse serum than with $2 \cdot 5-5.0 \%(\mathrm{v} / \mathrm{v})$ horse serum. Growth on agar was always better in air $+10 \%(\mathrm{v} / \mathrm{v}) \mathrm{CO}_{2}$ than in air alone. The amounts of growth in air varied between strains and sometimes within strains.

\section{Colonial and cellular morphology}

Examination of wet preparations by phase-contrast microscopy and of WrightLeishman-stained coverglass smears prepared from SBM culture sediment revealed myriads of pleomorphic organisms consisting of tiny spherules, ring forms approximately I $\mu$ diam., cocco-bacillary rods, and short smooth or beaded filaments. These were indistinguishable from those seen in mastitic udder secretions (Jasper et al. 1966).

Two colony forms were observed on agar plates for each strain of mycoplasma studied: the larger typical colonies $(0.3 \mathrm{~mm}$. average diam.) having a distinct raised centre and a thin peripheral zone, and the smaller granular colonies $(0.02 \mathrm{~mm}$. average diam.) without a peripheral zone. However, in the case of strain 1063 and Mycoplasma laidlawii, only the granular colonies were seen after 3 days of incubation, the larger colonies appearing after an additional week of incubation at room temperature. Surface 'crystallization' occurred near mycoplasma colonies of all strains examined except with strain I063 and $M$. laidlawii. It was more prominent and could be recognized grossly on relatively freshly poured PPLO plates or in the presence of heavy growth.

\section{Haemolysis}

All of the mycoplasmas were haemolytic for the red blood cells of each species tested. The most extensive haemolysis occurred with rabbit and guinea-pig red cells, in which case the margins of haemolytic zones were hazy. Clear haemolysis with sharp borders occurred with sheep, cow and horse red cells, sheep cells giving the sharpest reactions.

\section{Satellite growth}

Growth enhancement due to the presence of staphylococcal colonies was not observed on plates incubated in air $+\mathrm{I0} \%(\mathrm{v} / \mathrm{v}) \mathrm{CO}_{2}$ but was quite evident on plates incubated in air alone. Satellite growth enhancement was seen only with the strains associated with mastitis, but not with strains 1063, I367, I370, Mycoplasma bovigenitalium, M. pharyngis or $M$. laidlawii. Mycoplasma colonies in the vicinity of the staphylococcal colonies were more numerous and distinctly larger (2-4 times) than the more distant colonies. Consequently, this effect was usually easily visible grossly.

\section{Biochemical reactions}

Change in colour from red to yellowish orange (phenol-red indicator) was not observed in most of the sugar fermentation tubes. Therefore a decrease in $\mathrm{pH}$ value by $\mathrm{I} \cdot \mathrm{O}$ unit or more from that of the control tubes was considered to be evidence of carbohydrate fermentation. Mycoplasma laidlawii fermented starch, glycogen, dextrin, maltose, galactose, fructose and glucose, and strain 1063 fermented starch, dextrin, glycogen, maltose and glucose. All the other mycoplasma strains were regarded as nonfermenters. Gelatin was liquefied after I4 days only by strains I367, I370, Mycoplasma bovigenitalium, and $M$. pharyngis. All strains were catalase-negative. Tests for methylene-blue reduction were variable and not considered to be reliable. 


\section{Serological relationship}

Growth-inhibitory antibodies were detected in homologous antisera only to $\mathrm{Myco}$ plasma pharyngis, $M$. bovigenitalium, strain ' $56 \mathrm{R}$ ' and strain 1367 (Table 2). Growth inhibition was evident only against homologous strains and no cross-inhibition was observed.

Precipitating antibodies were detected in all homologous immune rabbit sera (Table 2). For comparative purposes, gel-diffusion patterns were arranged so that each of the PPLO broth-absorbed homologous antisera in a central cup was tested against all the mycoplasma antigens. These homologous and heterologous precipitation studies resulted in precipitin patterns which allowed some degree of antigenic grouping (Table 2). For the first six mycoplasmas listed in Table 2, each antiserum usually formed 2-3 precipitation lines against homologous and heterologous antigens within the group (Fig. I). At least one distinct dense band and two light bands were common to these six mycoplasmas as shown by the pattern of fusion. Cross reactions with the other strains were not seen.

Table 2. Antigenic relationship of various mycoplasma studied by gel-diffusion precipitation test

No. of precipitation lines with rabbit antisera to

\section{Mycoplasma antigen}

\begin{tabular}{|c|c|c|c|c|c|c|c|c|c|c|c|c|}
\hline 芯 & 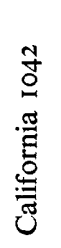 & 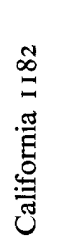 & 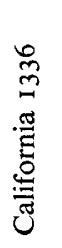 & 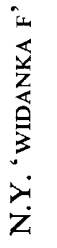 & 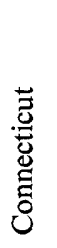 & $\begin{array}{l}04 \\
0 \\
0 \\
i \\
z i\end{array}$ & 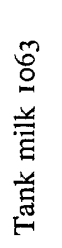 & 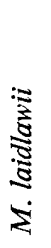 & 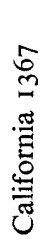 & 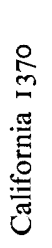 & 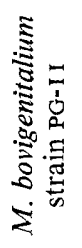 & 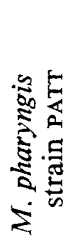 \\
\hline $2-4$ & $2-3$ & $2-3$ & $2-3$ & 3 & $\mathrm{I}-2$ & 0 & 0 & 0 & 0 & 0 & 0 & 0 \\
\hline$I-2$ & $I-3$ & $I-3$ & $2-3$ & I-3 & I-2 & 0 & 0 & 0 & 0 & 0 & 0 & 0 \\
\hline 2 & $2-3$ & $2-3$ & $2-3$ & 2 & $1-2$ & 0 & 0 & 0 & 0 & 0 & o & 0 \\
\hline $2-3$ & $2-3$ & 3 & 3 & $1-2$ & $I-2$ & 0 & 0 & 0 & 0 & 0 & o & 0 \\
\hline 2 & $2-3$ & 2 & 2 & $2-3$ & 2 & 0 & 0 & 0 & 0 & 0 & 0 & 0 \\
\hline $2-4$ & $2-3$ & 2 & $2-3$ & $2-3$ & 2 & 0 & 0 & 0 & 0 & 0 & 0 & 0 \\
\hline 0 & 0 & 0 & 0 & 0 & 0 & $2-3^{*}$ & 0 & 0 & 0 & 0 & 0 & 0 \\
\hline 0 & 0 & 0 & 0 & 0 & 0 & 0 & I & I & 0 & 0 & 0 & 0 \\
\hline 0 & 0 & 0 & 0 & 0 & 0 & o & 0 & 2 & 0 & 0 & 0 & 0 \\
\hline 0 & 0 & 0 & 0 & 0 & 0 & 0 & 0 & 0 & $2 *$ & 2 & 2 & 0 \\
\hline 0 & 0 & 0 & 0 & 0 & 0 & 0 & 0 & 0 & 2 & 3 & 3 & 0 \\
\hline 0 & 0 & 0 & 0 & 0 & 0 & o & 0 & o & 2 & 3 & $3^{*}$ & 0 \\
\hline 0 & 0 & 0 & 0 & 0 & 0 & 0 & 0 & 0 & 0 & 0 & 0 & $\mathrm{I}^{*}$ \\
\hline
\end{tabular}

The presence of common antigens was also evident in the group composed of vaginal strains 1367, I370, and Mycoplasma bovigenitalium (Table 2). Similar precipitation lines were obtained with antisera to $M$. bovigenitalium and strain 1370 (Fig. 2-4). These two mycoplasmas shared one diffuse broad band and two distinct narrow bands, whereas strain 1367 lacked the antigen causing the diffuse broad band. Antiserum to 1367 formed two distinct lines with homologous antigen and with strain 
1370, but only one distinct line with $M$. bovigenitalium. Cross-reactions with isolates from milk and with other strains were not observed.

Antiserum to strain I063, an isolate from bulk tank milk, formed a precipitation band with homologous antigen, and did not cross-react with Mycoplasma laidlawii (Table 2). However, antiserum to $M$. laidlawii produced two broad bands of precipitation with the homologous antigen and shared a faint thin precipitation line with strain 1063. Antisera to strain ' $56 \mathrm{R}$ ' and $M$. pharyngis formed a distinct precipitation line only against homologous antigens, and did not cross-react (Table 2 ).

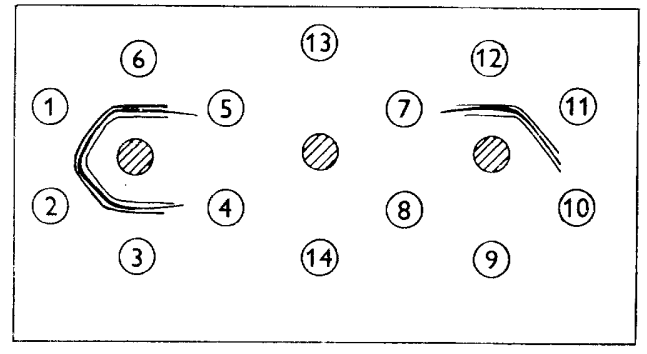

Fig. I

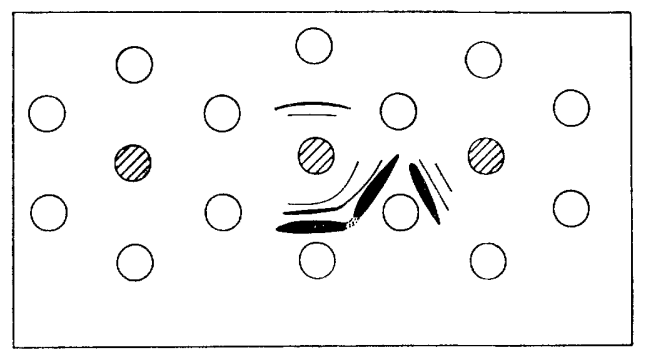

Fig. 3

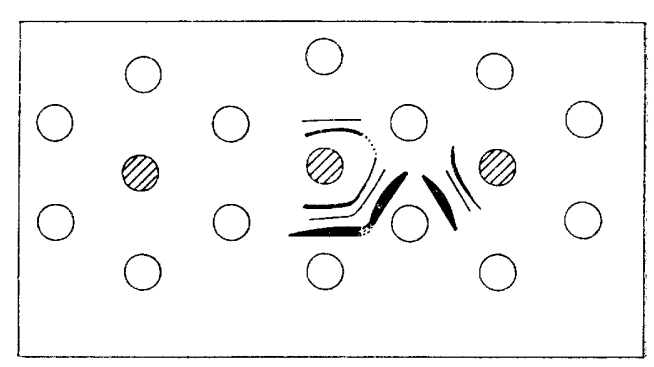

Fig. 2

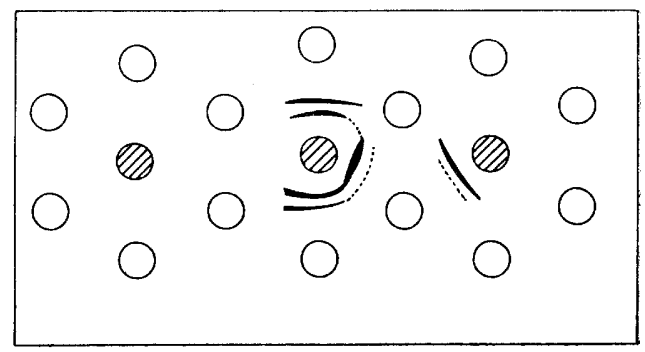

Fig. 4

Figs. 1, 2, 3, 4. Gel-diffusion precipitation patterns drawn from photographs taken after $40 \mathrm{hr}$ at $4^{\circ}$. Broken lines represent faint precipitation lines. The origin of each strain is indicated in Table $\mathbf{~}$. The outer wells were filled with the mycoplasma antigens arranged in the same numerical order in each case as is indicated on Fig. I and as follows: Well I, strain 1042; 2, strain I 182; 3, strain I336; 4, strain 1063; 5, M. laidlawii; 6, strain oI; 7, sediment from uninoculated PPLO broth (control); $8, M$. bovigenitalium strain PG-I I ; 9, $M$. pharyngis strain PATT; IO, N.Y. strain ' $56 \mathrm{R}$ '; I I, N.Y. strain 'WIDANKA F'; I2, Connecticut strain; 13, strain $1367 ; 14$, strain 1370 . The centre wells received different rabbit immune sera as follows: Fig. I, antiserum to strain 1042; Fig. 2, antiserum to $M$. bovigenitalium strain PG-II; Fig. 3, antiserum to strain 1370; Fig. 4, antiserum to strain 1367 .

To substantiate these serological relationships among the various mycoplasmas, the antisera were absorbed with selected mycoplasma antigens and again tested for homologous and heterologous precipitins. This study, although limited, showed the following. (I) All antisera absorbed with homologous antigens no longer formed precipitation lines with their respective antigens. (2) In the case of the first 6 mycoplasmas listed in Table 2: (a) precipitation lines were no longer formed against the heterologous antigens after absorption with homologous antigen; $(b)$ absorption of each of these six antisera with strain or antigen removed precipitins for all homologous and heterologous antigens; $(c)$ cross-absorption of each of these six antisera with other antigens, namely, 
strain '56R', strain 1063, Mycoplasma laidlawii and $M$. bovigenitalium did not remove precipitins. (3) Cross-absorption of antiserum to strain ' $56 \mathrm{R}$ ' with strain or and $M$. bovigenitalium antigens did not remove precipitins. (4) Homologous absorption of antiserum to $M$. laidlawii, removed cross-reacting antibody for strain I063. (5) Homologous absorption of antisera to vaginal strains 1367 and 1370 , and to $M$. bovigenitalium removed precipitating antibodies against both the heterologous and homologous strains. (6) Cross-absorption of antisera to vaginal isolates 1367 and 1370 and to $M$. bovigenitalium with strain oI and ' $56 \mathrm{R}$ ' antigens did not remove precipitins. Thus the mycoplasmas isolated in our laboratory and bovine strains from other sources appeared to fall into 4 serotypes (Table 3 ).

\section{Table 3. Serotypes of bovine mycoplasma strains based on precipitation patterns obtained by gel diffusion test}

Serotype
I
2
3
4

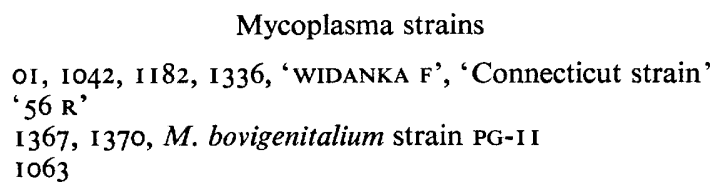

DISCUSSION

Although cultural, morphological and biochemical characteristics of mycoplasmas are not species-specific, a broad grouping into parasitic and saprophytic organisms was apparent on the basis of sugar fermentation and horse serum requirements (Freundt, 1958). The requirement of horse serum for growth on PPLO agar and the inability to ferment carbohydrates indicated that all our mycoplasma isolates associated with mastitis and with the vagina were parasitic. Recent experiments with the milk strain oI and the vaginal strain 1370 have shown that both are pathogenic when injected into the bovine udder.

Strain 1063 , an isolate from bulk milk, shared some cultural and biochemical characteristics common to saprophytic Mycoplasma laidlawii. These include limited carbohydrate fermenting capacity, growth (although poor) on PPLO agar without serum, small granular colonies after 3 days growth and no surface crystal formation. Gel-diffusion studies with immune sera against other mycoplasmas differentiated strain 1063 from those causing mastitis, but revealed an antigen possessed by $M$. laidlawii. Upon injection into one quarter of an experimental cow, strain I063 did not cause mastitis or establish infection. It is therefore probable that this strain entered the bulk tank milk from outside contamination rather than from udder infection, although mastitis-causing strains have been repeatedly demonstrated in the bulk tank milk of an infected herd (Jasper et al. 1966).

Satellite growth enhancement of mycoplasmas by a staphylococcus was seen only aerobically. Growth was enhanced for all mycoplasmas associated with mastitis whereas the vaginal, human and saprophytic strains studied were not influenced. This interaction between the staphylococcus and mycoplasma is poorly explored and needs further investigation.

Poor growth of vaginal isolates in PPLO broth as compared to that of other strains suggests a need for some additional growth factors or better cultural conditions. One other isolate from a bovine oviduct was lost during subculture, apparently because of 
inadequate growth conditions. Deoxyribonucleic acid was found essential for primary isolation of Mycoplasma bovigenitalium (Edward, 1954) and might prove to be helpful if routinely incorporated as a growth supplement in PPLO medium. Some of our recent experiments indicate that addition of Bacto supplement B (Difco) to PPLO broth markedly enhanced growth of vaginal mycoplasmas as well as of other strains.

Growth inhibition by specific immune serum was found to be reliable for identification and differentiation of human mycoplasmas because of the low order, or absence, of cross-reactivity as seen in complement-fixation tests (Clyde, 1964). Growthinhibitory antisera against many human (Clyde, 1964), porcine (Dinter et al. 1965) and bovine strains (Carmichael et al. 1963) have been produced successfully. We did not obtain growth-inhibitory antisera against the mycoplasmas studied with the exception of Mycoplasma bovigenitalium, M. pharyngis, strain ' $56 \mathrm{R}$ ' and strain $\mathrm{I} 367$; however, precipitating antibodies were detected in all antisera. Others have obtained growth-inhibitory antisera against $M$. bovigenitalium, strain ' $56 \mathrm{R}$ ', strain 'WIDANKA F' and the Connecticut strain by giving graded doses of antigens twice weekly over a period of 2-4 months (Carmichael et al. 1963). These variations in developing growthinhibitory antisera against different strains of mycoplasmas are not fully understood at present, but may depend upon the techniques and duration of immunization, and the time of harvesting serum during the course of immunization. Production of growthinhibitory antibodies is generally known to be difficult (Morton, 1966).

Unabsorbed immune rabbit sera gave faint precipitation lines when tested against PPLO broth as an antigen, indicating development of some non-specific precipitating antibodies to ingredients of the culture medium. These lines were no longer evident after the absorption of sera with lyophilized PPLO broth. Therefore, the precipitin patterns obtained with absorbed homologous and heterologous antisera tested against various mycoplasma antigens were considered specific, and not associated with the PPLO broth medium.

On the basis of the gel-diffusion patterns obtained with absorbed homologous and heterologous antisera, and the cross-absorption studies, the mycoplasmas isolated in our laboratory and the bovine strains from other sources could be placed in four serotypes (Table 3). The findings that mycoplasmas isolated from mastitic milk in California are related to the Connecticut strain and to a New York strain (strain 'WIDANKA F'), and that the strain ' $56 \mathrm{R}$ ' and Mycoplasma bovigenitalium are distinct serotypes, confirmed earlier observations with growth-inhibiting antisera (Carmichael et al. 1963). Our classification of these strains of bovine origin into four distinct serotypes has since been confirmed by Dr R. H. Leach (personal communication).

With the exception of strain $56 \mathrm{R}$, isolated from a single case of mastitis in New York (Carmichael et al. 1963) all studies reported on isolates from mastitis in the United States have indicated that a single and distinct strain is involved. The nomenclature previously suggested, Mycoplasma agalactiae var. bovis (Hale et al. 1962) does not appear to be appropriate since no close relationship to Mycoplasma agalactiae has been demonstrated. We therefore suggest that the term 'Mycoplasma bovimastitidis' be considered for this serotype.

Although some variation existed in the number of precipitation lines obtained with homologous and heterologous antisera to six mycoplasmas of sero-type I, at least 2-3 antigenic components common to all six strains were usually recognized. With a more sensitive diffusion technique, such as immunoelectrophoresis and starch-gel electro- 
phoresis, it might be possible to find and resolve some minor antigenic components specific to a particular strain or common to different strains.

The isolation of two vaginal mycoplasmas (strain 1367, 1370) having antigenic components common to Mycoplasma bovigenitalium was unexpected. $M$. pharyngis, an organism commonly cultured from the normal human oropharynx (Clyde, 1964), was antigenically unrelated to the bovine mycoplasmas tested. However, the spread of human mycoplasmas to cattle is an interesting possibility and may prove of significance if some of the human mycoplasmas are found to be carried by or pathogenic to cattle.

The authors wish to thank Dr E. J. Carroll for his valuable suggestions during the course of the investigations and $\mathrm{Dr} \mathrm{R}$. H. Leach for examining our isolates by serologic and other methods.

\section{REFERENCES}

BAR-Moshe, B. (1964). The isolation of Mycoplasma from an outbreak of bovine mastitis in Israel. Refuah vet. 2I, 99.

Bruford, J. W., Loosmore, R. M., Blackburn, P. S., Hughes, D. L., Pearson, J. K. L., Uvarov, O., White, J. B. \& Wilson, C. D. (1965). Controlling bovine mastitis. Vet. Rec. 17, 612.

Carmichael, L. E., Guthrie, R. S., Fincher, M. G., Field, L. E., Johnson, S. D. \& Lindquist, W. E. (1963). Bovine Mycoplasma mastitis. Proc. U.S. live Stk sanit. Ass. 67, 220.

ClYDE, W. A., JUN. (1964). Mycoplasma species identification based upon growth inhibition by specific antisera. J. Immunol. 92, 958.

Davidson, I. \& StUART, P. (I960). Isolation of a Mycoplasma-like organism from an outbreak of bovine mastitis. Vet. Rec. 72, 766 .

Dinter, Z., Danielsson, D. \& Bakos, K. (1965). Differentiation of porcine Mycoplasma strains. J. gen. Microbiol. 4I, 77.

EDwARD, D. G. FF. (1954). The pleuropneumonia group of organisms: a review, together with some new observations. J. gen. Microbiol. ro, 27.

Fincher, M. G. (1964). Mastitis associated with Mycoplasma. Vet. News, no. 3 (Sept.-Oct.).

FreundT, E. A. (1958). The Mycoplasmataceae, p. 50. Copenhagen: Munksgaard.

hale, H. H., Helmboldt, C. F., Plastridge, W. N. \& Stula, E. F. (1962). Bovine mastitis caused by a Mycoplasma species. Cornell Vet. 52, 582.

JASPER, D. E., JAIN, N. C. \& BraZIL, L. M. (I966). Clinical and laboratory observations on bovine mastitis due to Mycoplasma. J. Am. vet. med. Ass. 148, I017.

KoHN, J. (1953). A preliminary report of a new gelatin liquefaction method. J. clin. Path. 6, 249.

MAdOFF, S. (1959). Isolation and identification of PPLO. Ann. N.Y. Acad. Sci. 79, 383.

Morton, H. E. (1966). Mycoplasma-latex agglutination reaction. J. Bact. 92, I 196.

Morton, H. E., Smith, P. F. \& Leberman, P. R. (I949). Symbiotic growth of pleuropneumonia-like organisms with bacterial colonies. Proc. Soc. exp. Biol. Med. 72, 328.

O'Berry, P. A., Bryner, J. H. \& Frank, A. H. (I966). Isolation of Mycoplasma from an aborted bovine fetus and vaginal mucus. Am. J. Vet. Res. 27, 677.

STERN, D. N. \& HARRIs, W. K. (I964). Abstract of report on Mycoplasma (PPLO) mastitis investigations. Proc. 17 th Northeast Mastitis Conference.

Stuart, P., Davidson, I., Slavin, G., Edgson, F. A. \& Howell, D. (1963). Bovine mastitis caused by Mycoplasma. Vet. Res. 75, 59 .

TulLy, J. G. (1965). Biochemical, morphological, and serological characterization of Mycoplasma of murine origin. J. inf. Dis. I15, I7I. 